measure for the intense repression they undergo and also for the extraordinary amnesia for childhood years. That an exaggerated horror of incest is the hall-mark of homosexuals is still not recognized. Freud traced in detail the development of the early fragmentary manifestations of sexuality in childhood into the more recognizable adult form. It was this conclusion about infantile sexuality, and the deriving of all neuroses from conflicts about it, that evoked so much hostility to his work.

Another set of impulses in a state of repression may be grouped under the term "aggressive," and their exact status caused Freud much puzzlement. At first he was inclined to regard them as responses to certain frustrating situationsfor example, jealousy : the murderous wishes of a child against his father are a classical example. The problem of whether a primary aggressive or destructive instinct is to be recognized he long kept open. Towards the end of his life Freud postulated the much debated "death instinct," and connected aggressivity with the turning of this from within towards the outer world.

On the basis of the three cardinal concepts of the unconscious, of repression, and of infantile sexuality, Freud elaborated in immense detail numerous studies of the most diverse human activities, constantly throwing out suggestions which have only in part so far been followed up. They range from the unravelling of psychoneurotic symptoms and psychotic delusions to the education of children, from the origins of conscience and morality to the importance of early family relationships, from the sources of artistic creativeness to the origins of religious beliefs, from the evolution of savagery into what civilization we possess to the nature of the deficiencies so patent in this. One may fairly say that there is no aspect of human activity on which his insight has not thrown light.

\section{Freud's Influence}

Widely different opinions have been expressed concerning the extent of Freud's influence, and the more familiar one is with his work the more reticent is one in according the exaggerated claims that have often been made for it. People talk of the revolution in thought he inaugurated, the impossibility of conceiving our present world without his teaching, and so on. Very much of this is lip service, and psychoanalysts are much more impressed by the extent to which his work is even yet not accepted, still less applied. Nevertheless many ramifications of his influence can be traced socially. There is a vague recognition that dreams have some meaning, that one may betray private thoughts by a slip of the tongue which is no longer regarded as purely accidental, that our childhood life has fateful consequence for later years, that we do not always know what impels our conduct, and that perhaps our sexual wishes may produce indirect, disguised manifestations. Possibly a greater freedom in the discussion of sexual topics, including even perversions, and a greater tolerance in the judgment of delinquents may also be reckoned here, but I will confine myself to the more medical aspects of his influence.

The most striking of these would seem to be the vast extension of the scope of psychiatry, or medical psychology, that has been such a prominent feature of the past quarter of a century. There is a much wider recognition of the extent and significance of neurotic suffering than formerly. From the days when such a diagnosis was seldom and unwillingly made as a last resort, when even astigmatism or constipation could be excluded, we can now read reports from doctors who say that the sufferings of two-thirds of their patients are neurotic. Years ago it would never have occurred to the victim of an unhappy marriage to consult a psychiatrist, an everyday occurrence now. In such ways the medical profession is less exclusively materialistic than it used to be. But one does not note much advantage being taken of Freud's work in elucidating the pathological nature of neurotic symptoms. They are still often ascribed simply to overwork, and the sexual aetiology is still on the whole taboo.
Side by side with this is a freer admission that agencies roughly grouped as "emotional " probably play a considerable part in the causation of various physical conditions. Studies on the lines of what is called psychosomatic medicine have been made, particularly in America, with such different disorders as hypertension, duodenal ulcer, coronary thrombosis, and even some forms of eczema. There is undoubtedly much to learn in this field, which is peculiarly obscure, but I must subscribe to the criticism that the conclusions often put forward are so far greatly lacking in specificity.

There are many other extensions of psychiatry that could be mentioned: the analytic successes with some forms of psychosis in their early stages, the wide instituting of psychiatric child guidance clinics, the treatment and prophylaxis of delinquency, and so on. But I would conclude with the assertion that we are still far from assimilating and using all that Freud's work has to teach us.

\section{FREUD'S IMPACT ON PSYCHIATRY}

$$
\text { BY }
$$

\section{E. STENGEL, M.D., M.R.C.P.}

Reader in Psychiatry in the University of London; Professor-elect in Psychiatry in the University of Sheffield

There is no better proof of the great impact Freud has made on psychiatry than the change in its scope, for which his work has been largely responsible. Conventionally, psychiatry is defined as "the medical treatment of diseases of the mind." This definition no doubt satisfied our predecessors, whose orientation was well illustrated by Griesinger's dictum that mental diseases were brain diseases, and by Hughlings Jackson's warning that if there were such a thing as a disease of the mind we could do nothing for it. Nowadays both these dogmatic statements sound very much out of date. A great deal of the work that the present-day psychiatrist is doing is not medical in the conventional sense; an up-to-date definition of psychiatry focused on its therapeutic aspects would have to include psychological treatment: and the disorders treated by psychiatrists to-day embrace not only the mental illnesses which in days gone by were the province of the alienist, but also the vast range of the neuroses, which used to be the concern of the neurologist only, as well as a variety of personality disorders and social maladjustments which in the past did not come into the orbit of any branch of medicine. Psychiatry has more recently been defined as "the field of study which concerns disorders, defects and inadequacies of behaviour."1 Vague as this definition is, it does reflect the range of activity of the present-day psychiatrist.

\section{New Dimensions of Psychiatry}

Freud has not only expanded the range of psychiatry, he has also given it new dimensions in depth by the discovery and exploration of the dynamic unconscious-that is, of mental forces which influence behaviour and which can be brought into consciousness. Freud's chief domain was the study and treatment of the neuroses. By establishing their largely psychological origin and elaborating a treatment which is the basis of most psychotherapy he has greatly enriched psychiatry, but he also added immeasurably to the psychiatrist's labours. The psychopathological discoveries which resulted from the intensive study of the neuroses have

"Gregg, Alan, "What is Psychiatry?" British Medical Journal, 1944, 1, 550. 
illumined many aspects of the psychoses also. The first clinical psychiatrists to recognize this were Bleuler and Jung.

In the preface to his famous monograph, Bleuler in 1910 stated that his attempt to define schizophrenia psychopathologically was only an application of Freud's ideas, which had made many symptoms of that condition comprehensible. They had led to an understanding of the language of the delusions and hallucinations. This was the first time that Freud received recognition from official psychiatry. He had never worked in a psychiatric department. He approached the problem of the psychoses from an unexpected directionnamely, through the study of the dreams. Many a student of the human mind before Freud, and of course many poets, had noted the similarities between dreams and mental illness. Hughlings Jackson's remark, "Find out about dreams and you will find out about insanity," was known to Freud. But nobody before him had the courage and persistence necessary for this kind of exploration. Freud was fired and sustained in this work by the discovery that the dream was "the royal road to the unconscious."

The similarity of the mental functioning in dream and psychosis was always in his mind. "Dreams, as everyone knows, can be confused, unintelligible and positively senseless . . . we behave in them like insane people." And later, "A dream, then, is a psychosis with all the absurdities, delusions and illusions of a psychosis. No doubt it is a psychosis which has only a short duration, which is harmless and even performs a useful function. . . . We learn from it that even so deep-going a modification of mental life as this can be undone and can give place to normal mental functioning. Is it too bold to hope that it must also be possible to submit the dreaded spontaneous illnesses of the mind to our control and bring about a cure ?" This, then, was Freud's hypothesis : if the insanity of the dream was reversible, should it not be possible to reverse the insanity of the waking state ? It is, by the way, the same kind of hypothesis which underlies the research into "experimental psychoses" produced by drugs, which is again to the fore just now. However, Freud did not believe it possible to test this hypothesis of the reversibility of the psychoses with the help of the psycho-analytic method which required the patient's full co-operation.

In 1910, the year of the publication of Bleuler's monograph on the schizophrenias, Freud made an important direct contribution to the study of paranoid illness. $\mathrm{He}$ applied his newly won insight into unconscious mental processes and instinctual development in the analysis of the autobiography of a highly gifted paraphrenic patient which had raised quite a stir among psychiatrists. He subjected the rich psychopathological material contained in this book to the same kind of interpretation as his patient's neurotic symptoms and dreams. From this and other cases he came to regard repressed homosexuality as an important factor in paranoid states and he established the role of projection in the origin of delusions and hallucinations. He expressed the idea that these symptoms were not primary symptoms but manifestations of an attempt at self-cure-that is, a psychological healing mechanism. This functional concept has found wide acceptance among psychiatrists. It is reminiscent of Jackson's concept of positive symptoms as responses of the undamaged part of the brain.

\section{Structural Model of the Personality}

Freud's idea of the "anatomy of the mental personality" is one of the most widely known, one could almost say one of the most popular, psycho-analytic concepts. This structural schema appears deceptively simple, but the relationship between the three parts of the personality, as Freud saw it, is very complicated and does justice to the unity of the personality. The schema has often been attacked as fictitious and mechanistic. It has also been criticized as a misapplication of physiological concepts in psychology. It is true that the "mental apparatus" bears the unmistakable stamp of physiological thinking so familiar to Freud before he turned to psychopathology. It even bears a resemblance to Hughlings Jackson's schema of the anatomical and functional relationship between the "three levels of nervous arrangements," which Freud must have got to know when, in 1890 , he made a study of aphasia. He greatly admired Jackson, and there is reason to believe that the concepts of the evolution and dissolution of functions contributed to the foundations of psycho-analysis, although it is extremely unlikely that he was aware of the resemblance of his final schema of the structure of the personality, which he put forward in 1923 , to a neurophysiological schema which he had read about more than thirty years earlier. But it was the type of model which a medical man with his scientific background would devise in his search for a framework that would enable him to describe the complex interactions between different levels of mental functions.

Although Freud expressed the hope that some day it may be possible to establish a link between the functions of the different parts of his "mental apparatus" and parts of the brain, he regarded this "apparatus" as no more than a working hypothesis to be discarded when it was no longer useful, and he compared it with similar conceptual models in other sciences. "Such ideas as these are part of a speculative superstructure of psycho-analysis, any portion of which can be abandoned or changed without loss or regret the moment its inadequacy has been proved." The structural model of the personality has proved valuable to many psychiatrists describing the drives and conflicts within the personality under conditions of mental disorder.

\section{Biological Roots of Behaviour}

Freud had a remarkable gift for throwing new light on the familiar. His point of departure was usually a well-known clinical symptom. His short article, "Mourning and Melancholia," which has been one of the most thoughtprovoking of his writings, exemplifies this. He also showed an astounding boldness in modifying his own theories, sometimes without stating explicitly what he had discarded. Whatever may be thought about his "dualistic" instinct theory, it has proved extremely stimulating. His concept of the death instinct-he called it a biological speculationrepresents one of the few attempts at explaining the ubiquity of aggressive impulses in biological terms. It provided the semantic tools for studying aggression and guilt. Freud viewed normal human relations as the result of a successful fusion of libido with aggression, which he regarded as an expression of the death instinct. Many features of abnormal behaviour and of disturbed human relations were, in his view, manifestations of a de-fusion of those two basic drives. Here we have a conceptual framework within which a great number of behaviour disorders, including some caused by brain lesions, can be defined.

Ernest Jones ${ }^{2}$ summed up Freud's contribution to psychiatry by stating that psycho-analysis had provided it with an interpretative, a dynamic, and a genetic point of view. It had also made it comprehensible that the same symptoms could be produced by mental stress and by organic lesions : both were apt to lower the resistance to the break-through of imperfectly controlled unconscious impulses. "There is no contradiction whatever between the psychological and the organic point of view." This was already recognized by Freud in his study of aphasia. The general applicability of his concepts to disorders of behaviour, whatever their origin, has made them particularly valuable to neuropsychiatry. Paul Schilder's work is probably the best example of a successful synthesis of neurological with psycho-analytic concepts. The idea that psycho-analysis can illuminate psychogenic conditions only, and the converse implication that mental disorders to whose understanding or alleviation psycho-analysis can contribute must therefore be psychogenic, are widespread but erroneous.

${ }^{2}$ Ernest Jones, Papers on Psychoanalysis, 5th ed., 1948, p. 374 Bailliere, Tindall and Cox, London. 
Freud has often been accused of ignoring the role of innate endowment. It is true that he did not regularly refer to it. but he made his position abundantly clear on several occasions; for instance, in the following passage $(1949)^{3}$ : "The determining causes of the varying forms of human mental life are to be looked for in the interplay between inherited dispositions and accidental experiences. Thus it may happen that one particular instinct is innately too strong or too weak, and that one particular capacity is stunted or insufficiently developed in life, while on the other hand it may happen that external impressions and experiences may make stronger demands upon one individual than upon another. What the constitution of one person can deal with may prove an unmanageable task for another. These quantitative differences will determine the differences of the results."

This quotation shows that Freud did not believe in a single and simple aetiology of any mental disorder. Obviously "psychogenic" was ta him not identical with purely " environmental." He deplored the lack of knowledge about the relationship between constitution and traumatic experiences. His statements concerning this problem are in accord with the views of modern geneticists, who, for their part, have learnt to appreciate the significance of environmental factors even in the origin of hereditary illness. Possibly the time is not far off when psycho-analytically trained psychiatrists and geneticists, whose outlook and aims seemed incompatible not so long ago, will join forces to the great advantage of mental science. Such combined studies would be very much in keeping with Freud's views on what Francis Galton called the "relative powers of nature versus nurture." This is an area of psychiatric research in which Freud's influence has only just begun to make itself felt.

\section{Therapeutic Aspects}

Psycho-analysis is alone among the schools of psychology in that it developed as a method of treatment and has remained inseparably associated with that purpose. While the magnitude of Freud's contribution as an explorer of the mind is generally, though often grudgingly, recognized, even by those who reject many of his theories, the value of psycho-analysis as a therapy has not been easy to assess. It is superior to other psychological treatments, but convincing statistical proof of this superiority has not yet been established. Attempts at comparing the results of different psychological treatments with each other and with the outcome in untreated cases have, so far, proved unsatisfactory. The difficulties of obtaining control groups which could satisfy the requirements of both the statisticians and the therapists is much greater in psychiatry than in any other field. This applies to all treatments in psychiatry, physical and psychological.

Psycho-analysis proper is unrivalled as a tool of investigation into the mental life of individuals, but it is an unwieldy instrument which can be employed only in a very limited number of patients. In psychiatry a great variety of short methods of psychotherapy are being employed, and all of them have embodied some of the principles of psycho-analysis. They are often combined with physical treatments. Fread's observations about the doctor-patient relationship and its role in the therapeutic process have been invaluable far beyond psycho-analysis and psychotherapy.

The enormous demand for psychological treatment created by psycho-analysis has led to the development of group therapy, which owes a great deal to Freudian ideas. The concept of such a treatment appeared at first incompatible with that of psycho-analysis, which derives its effects from the complex relationship between a patient and a therapist. However, psycho-analytic theory, which Freud had applied to the psychology of larger social units, has been invaluable in that new therapeutic venture, which has proved unexpectedly popular with patients and psychiatrists alike.

'Freud, S., An Outline of Psychoanalysis, 1949, p. 50. Hogarth Press, London.
Two aspects in particular have been important in group treatment : the therapeutic role of interpersonal relationships between the members of the group and the therapist, and the identifications within the group.

The great significance of interpersonal relationships in psychiatry has recently been demonstrated in a joint research undertaken by a psychiatrist and a sociologist, both psychoanalytically trained, who closely studied a mental hospital community, including all ranks of staff. This work has opened up a new field for psychiatric and social studies which should benefit the patients as well as advance knowledge in social psychiatry. It has brought home to all engaged in mental hospital work that the effect they have on their patients does not depend only on the methods they employ: to understand the impact his methods make on his patients, the therapist has constantly to keep a close watch on himself, the observer. This applies not only to psychotherapy but also to the effects of drugs. Every controlled experiment has to take account of the factor of the doctor-patient relationship as a significant variable, the neglect of which has vitiated many a trial which otherwise satisfied the requirements of scientific standards. Psycho-analysis, in insisting on the importance of this factor in any situation involving interpersonal relations, has made a decisive contribution to psychology and psychiatry. It coincided with the recognition of the significance of the observer in the exact sciences.

Freud's influence has been very great in child psychiatry. Its rapid development is largely due to the impetus that psycho-analysis has given to the study of neurosis and behaviour disorder in childhood. Psycho-analysis has, from its beginnings, had a vested interest in this part of psychiatry : Freud's discoveries of the importance of childhood experiences in the neuroses of adults required to be supplemented by direct studies in children. Their importance for any measures of prevention goes without saying. Psycho-analytic studies in children have also made fundamental contributions to the knowledge of normal development.

\section{Outlook of Psychiatrists}

In widening the range of psychiatry, Freud has profoundly changed the outlook and the work of its practitioners. They are no longer satisfied with a mere description of their patients' symptoms, preceded only by a list of their previous illnesses. A proper psychiatric case history is a historical narrative in which traumatic childhood experiences, sexual conflicts, and other potentially pathogenic factors besides hereditary predisposition are given prominence. The time has gone when the psychiatrist, after having completed his ward rounds or having seen his patients in his clinic or consulting-room, could leave with the knowledge of having done his work, to his own satisfaction at least. To-day, however hard he works, he will rarely leave without the feeling that there are some patients who might have benefited from more psychotherapy than he could offer them. Freud has contributed a good deal to the narrowing of the gap which separates the mentally ill from the rest of the community. But this gap can be kept narrow and be even further reduced only by constant therapeutic contact, and much of it is psychotherapy. No wonder that psychiatrists often feel frustrated and that from time to time attempts are made to stem the growing demand for psychotherapy. Would it be surprising if some psychiatrists should secretly wish that Hughlings Jackson's warning that the mind was not the physician's concern had been heeded? But there is no going back. Nor is there an effective remedy for these difficulties in sight.

No doubt many more well-trained psychiatrists and psycho-analysts are required to meet the most urgent legitimate claims for psychological treatment. The authorities responsible for the medical curriculum are becoming alive to the need for a new orientation in the teaching of psychiatry. Knowledge of the problems of mental illness, especially of the neuroses, and of the principles of psychotherapy should enable general practitioners to play a much 
greater part in the treatment of these conditions than hitherto. But the demand for psychotherapy is likely to grow in proportion to the number of its practitioners and the quality of their results. Freud's work has led to an increased interest in the neuroses, and their enormous frequency in our civilization has been revealed. The serious social repercussions of neurotic morbidity have been recognized: it is responsible for more sickness and unhappiness than any other type of illness, and neurotic parents are likely to cause neuroses in their children. It is only natural that many psychiatrists pin their hopes on prevention. But the foundations of mental hygiene are still very much in need of strengthening by basic research. This is where the psycho-analyst can make his unique contribution and where sociology and anthropology are expected to come to the aid of psychiatry.

Freud never intended to revolutionize psychiatry. He never practised short methods of psychotherapy which are indispensable to the psychiatrist. He viewed the dilution of his method with concern. But once its basic principles had found acceptance in a growing number of psychiatric centres their application was dictated by the psychiatrists' requirements. Psychological treatment is being subjected to careful scrutiny and new ways of teaching it are being explored. Recording machines are being employed for studying the psychotherapeutic interview in detail, and the one-way screen and the microphone have broken the seclusion of the psychiatrist's consulting-room. Whether these new techniques, which have been difficult to reconcile with some accepted principles of psycho-analytic treatment, will bring new knowledge it is too early to say. They prove, at any rate, that modern psychiatry is not unduly conservative, but boldly experimental. It has its own momentum, and it is difficult to predict in what directions the application of Freud's work is going to develop.

Freud summarized the basic principles of psycho-analysis from time to time, but he left behind no textbook for psycho-analysts and psychiatrists to consult. He was aware of the unfinished character of his researches and never ceased to be a field worker in search of new knowledge. Looking back over his life's work, he said that he had made many beginnings and thrown out many suggestions. Their fruitfulness is far from exhausted. Freud's influence in psychiatry is likely to grow rather than to wane.

\section{MECHANICAL AND HAND SUTURE OF BLOOD VESSELS}

BY

\section{V. KOVANOV, M.D.}

Director of the School of Operational Surgery and

Topographical Anatomy of the First Moscow Order of Lenin Medical Institute

In recent years the surgery of the cardiovascular system has made great progress, and reports of successful operations on different parts of the heart and large vessels are being published all over the world. These operations have been made possible by the use of new instruments, apparatus, and other devices enabling the activity of organs and systems of vital importance to be controlled. The recent introduction of the method of hypothermia offers further facilities for the development of this branch of surgery.

As operations on the cardiovascular system are inseparable from the need to open the vascular trunks, the suturing of vessels and its technique have for long attracted the attention of surgeons. The first attempt to place a lateral suture on a vessel goes back to 1759 , when an English surgeon-Hallowell-succeeded in suturing a brachial artery which he had accidentally injured. His success led him to carry out experiments to verify his method of suturing vessels. Nevertheless this bold idea could not be put into practice because of the low level of medical and surgical science in those days, particularly as there were then no antiseptics. But the introduction of the antiseptic method at the end of the nineteenth century opened up new paths in surgery and made possible a return to the problem of vascular suture. The researches of Yassinovsky, published in 1889, played an important part in the development of this procedure. He proved experimentally that lateral suture of a vessel was a practical possibility, having failed to accomplish this in only four experiments out of a total of 26 . He later suggested a new method of suturing in which knot sutures were passed through only the outer coats of the vascular wall. These studies of Yassinovsky were followed by the publication of a number of experimental and clinical reports on the suturing of vessels, and thus a new physiological operation was introduced into surgery.

\section{Methods of Uniting Blood Vessels}

In this brief report it is not possible to discuss all the methods of uniting vessels that have been devised, more than 60 different modifications of the original procedure having been suggested. Many of them are only of historical interest, but others are of definite value as marking certain stages in the development of surgical thought. The methods of uniting vessels proposed may be divided into three groups : (1) those in which a hand-made ligature suture is used, including anastomosis by invagination, various methods of turning the suture, and eversion of the vessel walls ; (2) the prosthetic method, either alone or combined with a manual method ; and (3) mechanical suture by means of an apparatus which approximates the cut ends and joins them with tantalum clips.

In any particular operation the choice of a suture method must depend on the structure and situation of the vessel or vessels concerned. It would obviously be impossible to devise a universal method which would be equally suitable for the thoracic aorta and the femoral vein, for vessels of different diameter, for limb vessels or those which are relatively inaccessible. The method of uniting severed vessels most commonly used is by means of a hand-made ligature suture. A number of modifications of the circular suture were devised by Carrel at the beginning of the present century. Of these, according to Shumacker and Lowenberg (1948), the uninterrupted mattress suture with knot ligatures has given the best results. In experiments with this suture only $20.3 \%$ of complications occurred. Soviet surgeons too are working on this type of circular suture. In 1946 Sapozhnikov suggested a modification of the circular mattress suture-the welted suture which is inserted with two needles through the ends of the vessel with the intima everted. To facilitate turning the cuffs he made incisions $2 \mathrm{~mm}$. long. I myself have successfully employed this method in my clinical practice. Another modification of the circular suture technique was suggested by Polyantsev (1948). This is carried out in three stages: (1) three invertedU knot sutures are tied at equal distances from one another; (2) an uninterrupted twisted suture is inserted between them ; and (3) in order more effectively to seal the anastomosis the site of suture is enclosed in a "muff" of tissue taken from a nearby muscle, this "muff" being either separated from the muscle or left attached by a pedicle.

Experimenting with the thoracic aorta of a dog, Medvedjev (19.54) evolved a modification of an uninterrupted inverted-U suture in the form of a zigzag, which differs from an ordinary mattress suture in that each insertion of the needle into the everted edges of the vessel is made in the reverse direction to that of the suture itself, and the needle is withdrawn near or through the preceding stitch-hole. This 